\title{
Case Report: Spontaneous Pneumomediastinum an Unusual Complication of Covid-19 Infection in a Non-intubated Patient With Diffuse Bilateral Ground-glass Opacity: A Case Report of Progression of Disease During Self-isolation
}

\author{
Khosrow Agin $^{* *}$ (D, Tahereh Naghiloo ${ }^{1}$
}

1. Department of Internal Medicine, Faculty of Medicine, Shahid Beheshti University of Medical Sciences, Tehran, Iran

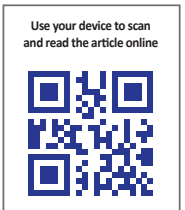

ditation: Agin K, Naghiloo T. Spontaneous Pneumomediastinum an Unusual Complication of Covid-19 Infection in a Non-intubated Patient With Diffuse Bilateral Ground-glass Opacity: A Case Report of Progression of Disease During Self-isolation. International Journal of Medical Toxicology and Forensic Medicine. 2021; 11(2):?-?. https://doi.org/10.32598/ijmtfm.v11i2.32679

dois'https://doi.org/10.32598/ijmtfm.v11i2.32679

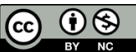

Article info:

Received: 25 Oct 2020

First Revision: 14 Nov 2020

Accepted: 14 Dec 2020

Published: 24 Aug 2021

\section{Keywords:}

COVID-19 infection, Spontaneous pneumomediastinum, Pneumonia, Forensic autopsy

\section{ABSTRACT}

Background: Spontaneous pneumomediastinum or mediastinal emphysema is relatively a rare disease that occurs in viral and bacterial infections with the benign entity.

Case: The patient was a 57-year-old man who, after a week of self-isolation at home, coming to the COVID-19 triage center of the hospital with severe shortness of breath. He was admitted to the Intensive Care Unit (ICU) due to acute respiratory failure. The patient was treated as the protocol designed and respiratory support with high flow nasal oxygen and Non-Invasive Positive Pressure Ventilation (NIPPV). Spontaneous pneumomediastinum was developed during viral pneumonia infection. The known risk factors included age, male sex, and abnormal laboratory finding. All the biochemical and hematological findings such as lymphopenia, thrombocytopenia, raised CRP, LDH, and ferritin were detected in our cases. They indicate a possible prognosis for the development of acute respiratory failure and adverse clinical outcomes.

Conclusion: Spontaneous pneumomediastinum has usually a benign outcome in COVID-19 Pneumonia and its prognosis is related to background conditions in patients.

Keywords: COVID-19 infection, Pneumomediastinum, Mediastinal emphysema, Pneumonia, Forensic autopsy

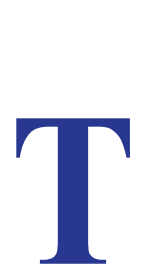

\section{Introduction}

he pneumomediastinum or mediastinal emphysema is defined based on the presence of free air in potential mediastinal space. The etiologic factors include trauma, spontaneous, idiopathic. Spontaneous Pneumomediastinum (SP) has a benign clinical course and is a rare disease. It also occurs in viral and bac- terial infections. The possible mechanisms are suggested Valsalva maneuver induced pressure within airways and diffuse alveolar damage and rupture. The frequency reported of SP is $6 \%$ in COVID - 19 pneumonia .

\section{Case Report}

The patient was a 57-year-old man who had a history of involving Coronavirus (COVID-19) infection before

* Corresponding Author:

Khosrow Agin, MD.

Address: Department of Internal Medicine, Faculty of Medicine, Shahid Beheshti University of Medical Sciences, Tehran, Iran Tel: +98 (21) 55413424

E-mail:khosrow.agin@yahoo.com;Agin@sbmu.ac.ir 
being admitted to the COVID-19 triage screening center. The clinical symptoms were a low-grade fever, shortness of breath, palpitations, general body aches, and malaise. He was isolated and managed according to the public health system policy at home for one week. the chief compliance was shortness of breath incoming from the hospital emergency department of COVID-19. Clinical signs included tachypnea $=22 \mathrm{~min}$, tachycardia $=122$ min, and oxygen saturation $=85 \%$. The patient was admitted to the pre-intensive care unit ward and treated with medications such as Remdesiver, interferon, methylprednisolone, and antibiotics based on the designed protocol in the hospital.

The initial biochemistry and hematology data consisted of the following: FBS=210 mg/dL, Urea=59 mg/ $\mathrm{dL}$, Creatinine $=1.1 \mathrm{mg} / \mathrm{dL}, \mathrm{LDH}=715 \mathrm{U} / \mathrm{L}, \mathrm{Na}=134$ $\mathrm{mEq} / \mathrm{L}, \mathrm{K}=5.2 \mathrm{mEq} / \mathrm{L}, \mathrm{WBC}=28.4 \times 10^{3} / \mu \mathrm{L}$, lymphocyte $=2.4 \times 10^{3} / \mu \mathrm{L}, \mathrm{RBC}=4.4 \times 10^{6} / \mu \mathrm{L}$, hemoglobin $=14.3$ $\mathrm{g} / \mathrm{dL}$, hematocrit $=41.2 \%$, platelets $=233 \times 10^{3} / \mu \mathrm{L}, \mathrm{RDW}$ $\mathrm{pc}=11.7, \mathrm{PDW}=15,6, \mathrm{MPV}=9.3$, fibrinogen=436 mg/ $\mathrm{dL}$, ferritin $=626 \mathrm{ng} / \mathrm{dL}, \mathrm{CRP}=49.6 \mathrm{mg} / \mathrm{dL}$, and $\mathrm{ESR}=44$ $\mathrm{mm} / \mathrm{h}$. The Blood gas analysis showed $\mathrm{PH}=7.40$, $\mathrm{PCO} 2=33 \mathrm{~mm} \mathrm{Hg}, \mathrm{Pao} 2=19.1 \mathrm{~mm} \mathrm{Hg}, \mathrm{HCO} 3=21.7$, $\mathrm{O} 2 \mathrm{Sat}=37.1 \%, \mathrm{Be}=-4$.

In the course of therapy, significant laboratory changes other than the progress of hypoxemia consisted of the hematologic data. Polymorphonuclear cells and white blood cell count (between 20000-3400) have remained predominantly high in the following days. Platelet count also changed and progressively decreased.

Chest-imaging manifested the exacerbation of radiological signs of ground-glass opacity and organized pneumonia diffusely in both lung fields. The pneumomediastinum appeared at this stage. Figures 1, 2, 3, 4,

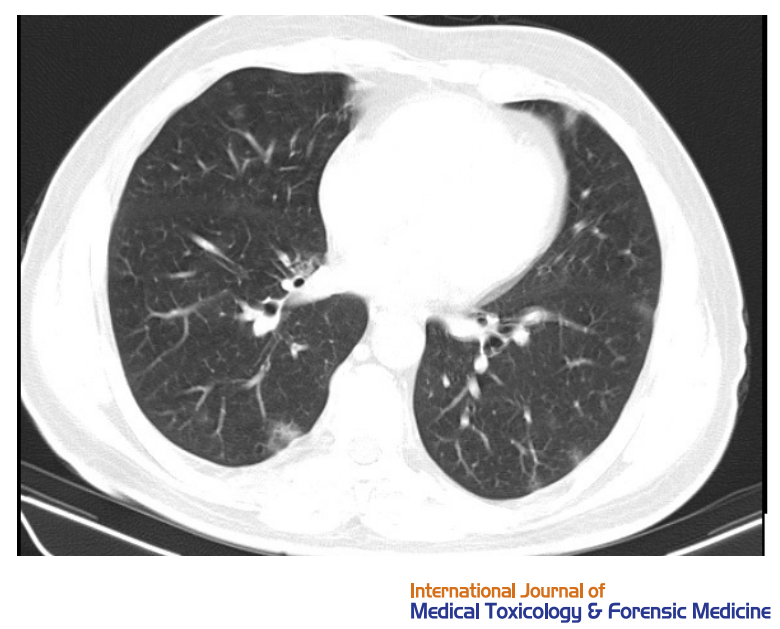

Figure 1. The CT scan finding of early coronavirus infection and 5 show chest CT imaging in the different views of progressive radiographic signs and spontaneous pneumomediastinum.

The patient's clinical conditions gradually aggravated in the following week despite ventilatory support with high flow nasal oxygen and non-invasive positive pressure ventilation. The exacerbation of shortness of breath and severe hypoxemia led to endotracheal intubation and the application of a mechanical ventilation setting. The patient expired a few days later in the ICU.

\section{Discussion}

COVID-19 infection originated at Wuhan city of China and quickly became a worldwide pandemic in 2019 [1]. This condition is currently a serious health threat. The associated clinical symptoms include a wide range, from asymptomatic infections and viral pneumonia to severe acute respiratory failure, and even death.

The known risk factors include age, male gender, laboratory abnormalities, and co-morbid diseases [2]. Frequent associations have been reported between COVID-19 infection and other diseases that either exacerbate the underlying conditions or cause acute forms of the disease [3-7]. COVID -19 infection is a multiorgan disease. These manifestations are ranged from maternal and perinatal involvement [8] to various organ involvements, such as the cardiovascular system, nervous system, gastrointestinal system, and liver [9], and so on.

The remarkable clinical manifestation of COVID-19 is contaminated by the respiratory system [10] and ranges from asymptomatic to severe Acute Respiratory Distress Syndrome (ARDS), and death. The cardinal clinical symptoms include the following: fever (89\%), cough

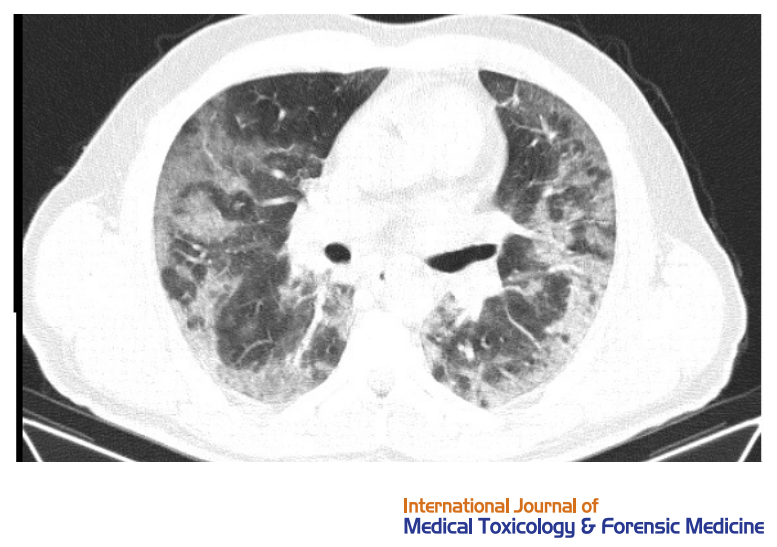

Figure 2. The diffuse bilateral Ground Glass opacity of COVID-19 CT scan 


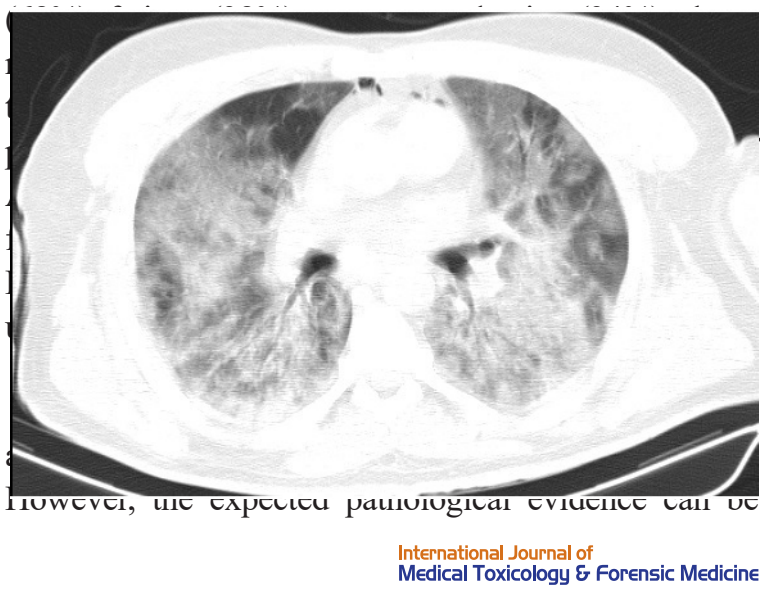

Figure 3. The early upper mediastin sponteaneus pneumothorax CT image

based on the reported experiences, as follows. The gross sections of the lung may present diffuse firm and rubbery parenchyma with alveolar edema and the bronchial airway filled with mucus plaque. Lung tissue staining may disclose hyaline membrane formation, proteinaceous exudates, and fibrin deposition in alveolar spaces. Besides, fresh thrombi in the pulmonary artery and hyalin microthrombi in the capillaries were reported in the autopsy $2[12,13]$. Figures 6 , and 7, present the different postmortem examinations of Covid-19.

The hematologic abnormalities are reported as lymphocytopenia $(83.3 \%)$, thrombocytopenia (36.1\%), and leukopenia $(33.7 \%)$. The biochemical parameters reflected the rising frequency of CRP (60.7\%), LDH (41\%), and ferritin, respectively. The current study presented an association between hematologic and biochemistry data abnormality with lymphopenia, elevated ferritin level, increased LDH and CRP levels, and ARDS [14]. Our case manifested recent para-clinical abnormality.

Chest imaging is necessary for the follow-up management and treatment of coronavirus infection. CT scan presents a rapid and highly-positive rate in the diagnosis of the COVID-19 in 90\%-95\% of cases [15].

Chest $x$-ray in the early stages of the disease fails to provide much clinical information; however, with progression, the disease manifests radiographic signs of ARDS. CT scan is more optimal imaging in the course of pulmonary manifestation of coronavirus infection, compared to the chest X-ray [16]. Available radiographic CT signs include Ground Glass Opacity (GGO) in $88.9 \%$, which can have a diverse distribution in the pulmonary fields. It may include bilateral (87.5), peripheral (76\%), and multilobular involvements (78.8\%). Besides, isolated GGO

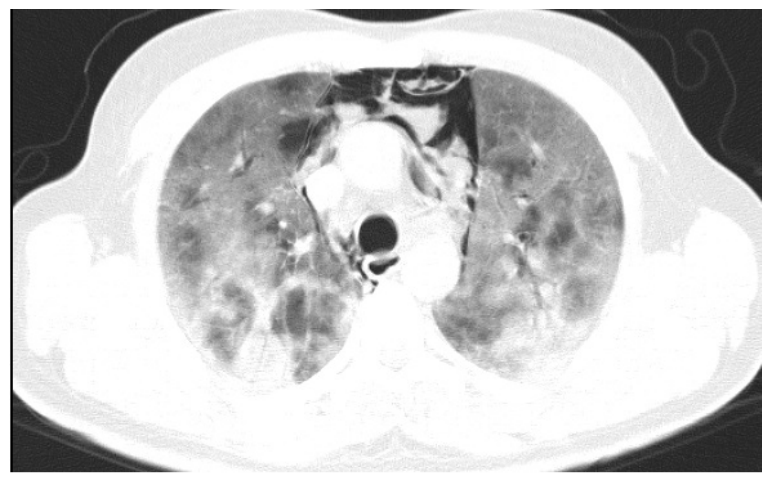

International Journal of Medical Toxicology \& Forensic Medicin

Figure 4. Upper mediastin spontenous pneumothorax in COVID-19 pneumonia

and in combination with consolidative opacity are the most common presentations in the COVID-19-related CT scans. The uncommon CT scan presentation of coronavirus infection discloses interlobular septal thickening, crazy-paving pattern, parenchymal band, consolidated opacity surrounded by GGO, reversal halo sign, air trapping, air bronchogram, pleural effusion, mediastinal lymphadenopathy [17], and nodules. CT scan findings initially revealed the limited GGO in the peripheral field of pulmonary parenchyma in our case; it was then progressively diffused to the central zone.

Pneumothorax (air leak) is defined as the presence of air in the pleural space. Its pathogenesis is due to the rupture of the alveoli and the passage of air into the space adjacent to the pleura (pneumothorax). It could also be through the bronchoalveolar sheath to the mediastinal space, in which case it is called pneumomediastinum. The causes have been divided on an etiologic basis and included spontaneous and traumatic aspects.

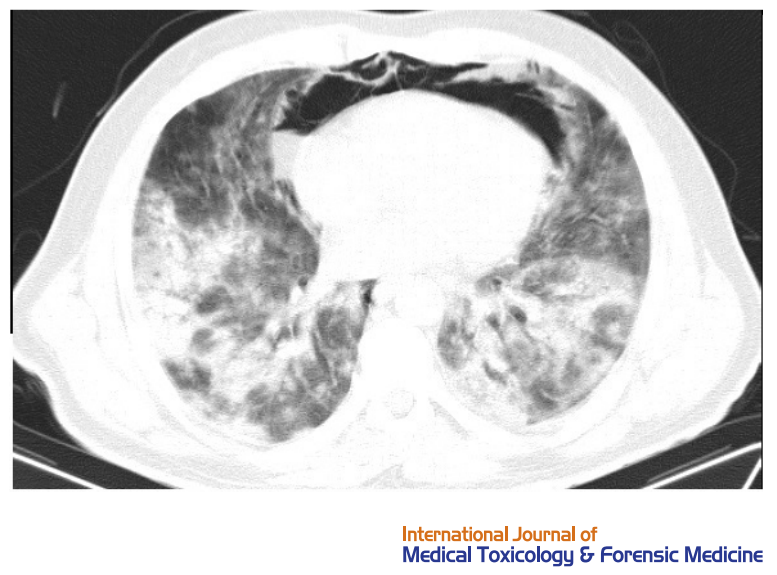

Figure 5. Lower mediastin spontenous pneumothorax in COVID-19 pneumonia 


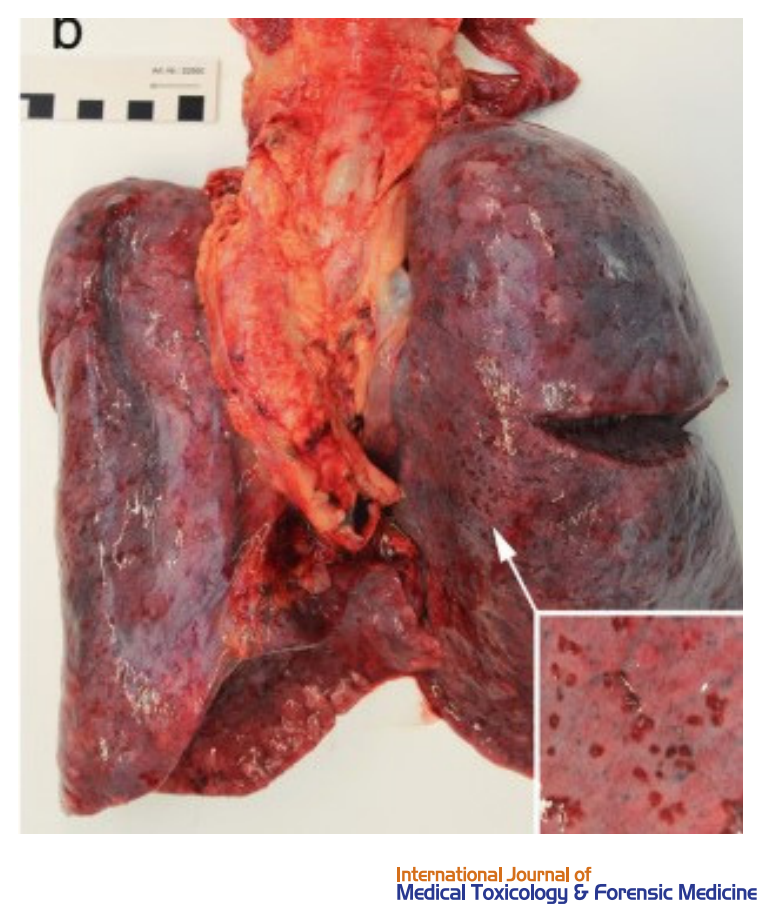

Figure 6. Gross COVID-19 lung postmortem view

The picture was copied from the article of Int J Legal Med. 2020 Jun 5: 1-6.

The primary or secondary spontaneous form is related to the structural abnormality of respiratory system development. The traumatic etiology of pneumothorax may be produced as iatrogenic (medical procedure) and nonpathogenic (blunt or penetrating trauma) [18]. The annual prevalence spontaneous of it was reported as 36-66 per 100000 individuals. Besides, it was associated with a male-to-female ratio of 4-10/1 [19]. The peak age prevalence consisted of 15-34 and over 65 years, respectively, and up to $50 \%$ of those hospitalized. Clinical features may range from silent (occult) to emergent conditions.

Pneumomediastinum is an unusual complication of viral pneumonia in COVID-19 disease. In the past year with widespread COVID-19, a few cases were reported as spontaneous pneumomediastinum [20-24]. It has occurred in high frequency amongst patients with trauma and mechanical support ventilation. Pneumomediastinum is most common in male patients $(>60 \%)$ and detected in over $30 \%$ of cases with comorbid diseases [25]. Spontaneous pneumomediastinum was detected in the non-intubated condition in our case [26] and the CT imaging of COVID-19 viral pneumonia indicated the bilateral diffuse of GGO [27]. These data were compatible with the recently reported studies.

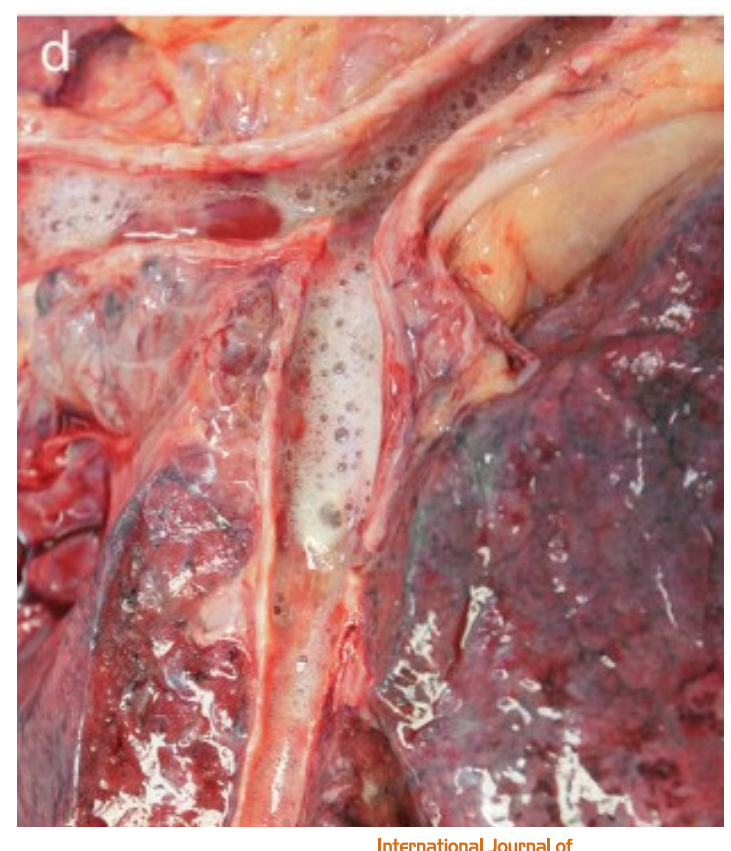

Medical Toxicology \& Forensic Medicine

Figure 7. The vitual view of bronchilal airway of COVID-19 case

The picture was copied from the article of Int J Legal Med. 2020 Jun 5: 1-6.

\section{Conclusion}

Attention to all biochemical and hematology abnormal findings indicates that the prognostic, severity and development of COVID-19 pneumonia complications could predict the occurrence of pneumothorax.

\section{Ethical Considerations}

\section{Compliance with ethical guidelines}

All ethical principles were considered in this article. The participant was informed about the purpose of the research and its implementation stages; they were also assured about the confidentiality of their information; Moreover, They were allowed to leave the study whenever they wish, and if desired, the results of the research would be available to them. All authors read and accepted the publication conditions of the article.

\section{Funding}

This research did not receive any grant from funding agencies in the public, commercial, or non-profit sectors.

\section{Author's contributions}

Both authors equally contributed in preparing this article. 


\section{Conflict of interest}

The author declared no conflicts of interest.

\section{Acknowledgments}

The authors thank the triage center of COVID-19 at Loghman Hospital for providing the patient's information. Moreover, we would like to thank the patient's wife for agreeing with the publication of their patient's data.

\section{References}

[1] Kannan S, Shaik Syed Ali P, Sheeza A, Hemalatha K. COVID-19 (Novel Coronavirus 2019): Recent trends. Eur Rev Med Pharmacol Sci. 2020; 24(4):2006-11. [DOI:10.26355/eurrev_202002_20378] [PMID]

[2] Suess CH, Hausmann R. Gross and histopathological pulmonary findings in a COVID-19 associated death during selfisolation. Int J Legal Med. 2020; 134(4):1285-90. [DOI:10.1007/ s00414-020-02319-8] [PMID] [PMCID]

[3] Berger JR. COVID-19 and the nervous system. J Neurovirol 2020; 26(2):143-8. [DOI:10.1007/s13365-020-00840-5] [PMID] [PMCID]

[4] Kochi AN, Tagliari AP, Forleo GB, Fassini GM, Tondo C. Cardiac and arrhythmic complications in patients with COVID-19. J Cardiovasc Electrophysiol. 2020; 31(5):1003-8. [DOI:10.1111/jce.14479] [PMID] [PMCID]

[5] Bansal M. Cardiovascular disease and COVID-19. Diabetes Metab Syndr. 2020; 14(3):247-50. [DOI:10.1016/j. dsx.2020.03.013] [PMID] [PMCID]

[6] Wong SH, Lui RN, Sung JJ. Covid-19 and the digestive system. J Gastroenterol Hepatol. 2020; 35(5):744-8. [DOI:10.1111/ jgh.15047] [PMID]

[7] Trejo-Gabriel-Galán JM. [Stroke as a complication and prognostic factor of COVID-19(Spanish)]. Neurologia. 2020; 35(5):318-22. [DOI:10.1016/j.nrl.2020.04.015] [PMID] [PMCID]

[8] Zaigham M, Andersson O. Maternal and perinatal outcomes with COVID-19: A systematic review of 108 pregnancies. Acta Obstet Gynecol Scand. 2020; 99(7):823-9. [DOI:10.1111/ aogs.13867] [PMID] [PMCID]

[9] Lee IC, Huo TI, Huang YH. Gastrointestinal and liver manifestations in patients with COVID-19. J Chin Med Assoc. 2020; 83(6):521-3. [DOI:10.1097/JCMA.0000000000000319] [PMID] [PMCID]

[10] Singhal T. A review of Coronavirus disease-2019 (COVID-19). Indian J Pediatr. 2020; 87(4):281-6. [DOI:10.1007/ s12098-020-03263-6] [PMID] [PMCID]

[11] Udugama B, Kadhiresan P, Kozlowski HN, Malekjahani A, Osborne M, Li VYC, et al. Diagnosing COVID-19: The disease and tools for detection. ACS Nano. 2020; 14(4):3822-35. [DOI:10.1021/acsnano.0c02624] [PMID] [PMCID]
[12] Ackermann M, Verleden SE, Kuehnel M, Haverich A, Welte T, Laenger F, et al. Pulmonary vascular endothelialitis, thrombosis, and angiogenesis in Covid-19. N Engl J Med. 2020 383(2):120-8. [DOI:10.1056/NEJMoa2015432] [PMID] [PMCID]

[13] Wichmann D, Sperhake JP, Lütgehetmann M, Steurer S, Edler C, Heinemann A, et al. Autopsy findings and venous thromboembolism in patients with COVID-19: A prospective cohort study. Ann Intern Med. 2020; 173(4):268-77. [DOI:10.7326/M20-2003] [PMID] [PMCID]

[14] Terpos E, Ntanasis-Stathopoulos I, Elalamy I, Kastritis E, Sergentanis TN, Politou M, et al. Hematological findings and complications of COVID-19. Am J Hematol. 2020; 95(7):834-47. [DOI:10.1002/ajh.25829] [PMID] [PMCID]

[15] Dai WC, Zhang HW, Yu J, Xu HJ, Chen H, Luo SP, et al. [CT imaging and differential diagnosis of COVID-19(French)]. Can Assoc Radiol J. 2020; 71(2):195-200. [DOI:10.1177/0846537120913033] [PMID] [PMCID]

[16] Salehi S, Abedi A, Balakrishnan S, Gholamrezanezhad A. Coronavirus disease 2019 (COVID-19): A systematic review of imaging findings in 919 patients. AJR Am J Roentgenol. 2020; 215(1):87-93. [DOI:10.2214/AJR.20.23034] [PMID]

[17] Li Y, Xia L. Coronavirus disease 2019 (COVID-19): Role of chest $\mathrm{CT}$ in diagnosis and management. AJR Am J Roentgenol. 2020; 214(6):1280-6. [DOI:10.2214/AJR.20.22954] [PMID]

[18] Arshad H, Young M, Adurty R, Singh AC. Acute pneumothorax. Crit Care Nurs Q. 2016; 39(2):176-89.[DOI:10.1097/ CNQ.0000000000000110] [PMID]

[19] Kim D, Jung B, Jang BH, Chung SH, Lee YJ, Ha IH. Epidemiology and medical service use for spontaneous pneumothorax: A 12-year study using nationwide cohort data in Korea. BMJ Open. 2019; 9(10):e028624. [DOI:10.1136/bmjopen-2018-028624] [PMID] [PMCID]

[20] Al-Azzawi M, Douedi S, Alshami A, Al-Saoudi G, Mikhail J. Spontaneous subcutaneous emphysema and pneumomediastinum in COVID-19 patients: An indicator of poor prognosis? Am J Case Rep. 2020; 21:e925557. [DOI:10.12659/ AJCR.925557] [PMID] [PMCID]

[21] Mohan V, Tauseen RA. Spontaneous pneumomediastinum in COVID-19. BMJ Case Rep. 2020; 13(5):e236519. [DOI:10.1136/bcr-2020-236519] [PMID] [PMCID]

[22] López Vega JM, Parra Gordo ML, Diez Tascón A, Ossaba Vélez S. Pneumomediastinum and spontaneous pneumothorax as an extrapulmonary complication of COVID-19 disease. Emerg Radiol. 2020; 27(6):727-30. [DOI:10.1007/s10140-02001806-0] [PMID] [PMCID]

[23] Zhou C, Gao C, Xie Y, Xu M. COVID-19 with spontaneous pneumomediastinum. Lancet Infect Dis. 2020; 20(4):510. [DOI:10.1016/S1473-3099(20)30156-0] [PMID] [PMCID]

[24] Wang W, Gao R, Zheng Y, Jiang L. COVID-19 with spontaneous pneumothorax, pneumomediastinum and subcutaneous emphysema. J Travel Med. 2020; 27(5):taaa062. [DOI:10.1093/jtm/taaa062] [PMID] [PMCID]

[25] Wang J, Su X, Zhang T, Zheng C. Spontaneous pneumomediastinum: A probable unusual complication of Coronavirus disease 2019 (COVID-19) pneumonia. Korean J Radiol. 2020; 21(5):627-8. [DOI:10.3348/kjr.2020.0281] [PMID] [PMCID] 
[26] Manna S, Maron SZ, Cedillo MA, Voutsinas N, Toussie D, Finkelstein M, et al. Spontaneous subcutaneous emphysema and pneumomediastinum in non-intubated patients with COVID-19. Clin Imaging. 2020; 67:207-13. [DOI:10.1016/j. clinimag.2020.08.013] [PMID] [PMCID]

[27] Vela Colmenero RM, de Guzmán MDPG, de la Torre MCM. [Spontaneous pneumothorax and pneumomediastinum in bilateral pneumonia due to COVID-19 (Spanish)]. Med Intensiva. 2020; 44(9):591-2. [DOI:10.1016/j.medin.2020.05.020] [PMID] [PMCID] 